Wolfgang C. Ummenhofer MD, Christoph Kindler MD, Gabriela Tschalèr $\mathrm{MD}$, Karl F. Hampl MD, Juergen Drewe MD, Albert Urwyler MD

\section{Propofol reduces succinylcholine induced increase of masseter muscle tone}

Purpose: Succinylcholine is known to increase the tone of the masseter muscles. As excessive jaw tension may complicate rapid sequence induction, we investigated three induction techniques, all including the use of succinylcholine, with respect to masseter muscle tone, neuromuscular blockade, intubation conditions, and time course of intubation.

Methods: Sixty adult patients were allocated to one of three induction groups: Group THIO received $5 \mathrm{mg} \cdot \mathrm{kg}^{-1}$ thiopentone, Group THIO/ATR received $5 \mathrm{mg} \cdot \mathrm{kg}^{-1}$ thiopentone plus $0.05 \mathrm{mg} \cdot \mathrm{kg}^{-1}$ atracurium for precurarization, and Group PROP received $2.5 \mathrm{mg} \cdot \mathrm{kg}^{-1}$ propofol. All patients received $3 \mu \mathrm{g}^{\prime} \mathrm{kg}^{-1}$ fentanyl and $1.5 \mathrm{mg} \cdot \mathrm{kg}^{-1}$ succinylcholine. Time for induction of anaesthesia was recorded, and, after inserting a Grass Force Transducer between upper and lower incisors, jaw tone and the time course of jaw tension was recorded before and after the administration of succinylcholine.

Results: No differences in the onset of sleep were observed among the three groups (Group THIO $33 \pm 2$ sec: THIO/ATR $30 \pm 2 \mathrm{sec}$ : PROP $35 \pm 2 \mathrm{sec}$, mean \pm SE). Masseter preloads following induction of anaesthesia were similar in all three groups (THIO $16.4 \pm 2.1 \mathrm{~N}$ : THIO/ATR $15.1 \pm 2.0 \mathrm{~N}:$ PROP $12.7 \pm 1.6 \mathrm{~N}$ ). However, after administration of succinylcholine, the increase in masseter tone was less in Groups PROP (5.0 \pm I.I N) and THIO/ATR $(6.4 \pm 2.1 \mathrm{~N})$ than in Group THIO $(12.4 \pm 3.0 \mathrm{~N} ; P<0.05)$.

Conclusion: Jaw tension after administration of succinylcholine is influenced by the choice of induction agent. The increase of masseter muscle tone is lower following propofol or thiopentone/atracurium induction than with thiopentone alone.

Objectif : La succinylcholine est connue pour augmenter le tonus des muscles masséter. Comme une tension excessive sur la mâchoire peut compliquer une induction en séquence rapide, nous avons évalué trois techniques d'induction, incluant toutes de la succinylcholine, quant au tonus du masséter, au bloc neuromusculaire, aux conditions d'intubation et au délai de l'intubation.

Méthodes : Soixante patients adultes ont été répartis en trois groupes selon l'induction : le groupe THIO a reçu $5 \mathrm{mg} \cdot \mathrm{kg}^{-1}$ de thiopental, le groupe THIO/ATR a reçu $5 \mathrm{mg} \cdot \mathrm{kg}^{-1}$ de thiopental plus $0,05 \mathrm{mg} \cdot \mathrm{kg}^{-1} \mathrm{~d}^{\prime}$ atracurium comme précurarisation et le groupe PROP a reçu $2,5 \mathrm{mg} \cdot \mathrm{kg}^{-1}$ de propofol. Tous les patients ont par ailleurs reçu $3 \mu \mathrm{g} \cdot \mathrm{kg}^{-1}$ de fentanyl et $1,5 \mathrm{mg} \cdot \mathrm{kg}^{-1}$ de succinylcholine. Le temps requis pour l'induction a été noté et, après insertion d'un dynamomètre Grass entre les incisives supérieures et inférieures, le tonus de la mâchoire et l'évolution dans le temps de cette tension ont été notés avant et après l'administration de succinylcholine.

Résultats : Aucune différence n'a été observée entre les groupes concernant l'induction : le groupe THIO $33 \pm$ $2 \mathrm{sec}$, le groupe THIO/ATR $30 \pm 2 \mathrm{sec}$, le groupe PROP $35 \pm 2 \mathrm{sec}$, moyenne $\pm E T$. La précharge des masséters suite à l'induction était la même dans les 3 groupes: THIO 16,4 $\pm 2,1 \mathrm{~N}$, THIO/ATR I5, I $\pm 2,0 \mathrm{~N}, \mathrm{PROP} 12,7$ I, $6 \mathrm{~N}$. Cependant, suite à l'administration de succinylcholine, l'augmentation du tonus des masséters était moindre dans les groupes PROP $(5,0 \pm 1,1 \mathrm{~N})$ et THIO/ATR $(6,4 \pm 2,1 \mathrm{~N})$ que dans le groupe THIO $(12,4 \pm 3,0$ $\mathrm{N} ; P$ 0,05).

Conclusion : La tension du maxillaire après l'administration de succinylcholine est influencée par le choix des agents d'induction. L'augmentation de tonus des masséters est moindre suite à une induction au propofol ou au thiopental/atracurium qu'au thiopental seul.

From the Departments of Anaesthesia and Research, University of Basel, Kantonsspital, CH-4031 Basel, Switzerland. Address correspondence to: Wolfgang Ummenhofer MD; Phone: 41-61-265-7254; Fax: 41-61-265-7320;

E-mail: ummenhoferwoubaclu.unibas.ch Accepted for publication February 9, 1998. 


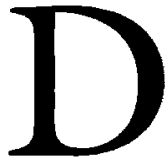
UE to its agonistic properties, succinylcholine (SCh) may increase the tone of the jaw muscles to a marked degree, ${ }^{1}$ leading to potentially difficult intubation conditions. For a reduction of muscle fasciculations, pretreatment with a non-depolarizing muscle relaxant has been proposed, but even a small dose of a non-depolarizing muscle relaxant may increase the risk of aspiration. ${ }^{2}$

Propofol has been shown to decrease muscle tone slightly in clinical use. ${ }^{3}$ For healthy, premedicated patients with favourable airway anatomy, the administration of hypnotics without neuromuscular blockade for induction of anaesthesia provides adequate conditions for tracheal intubation. ${ }^{3,4}$

For rapid sequence induction (RSI) of anaesthesia, SCh remains the "gold standard" of many institutions for achieving rapid and profound loss of muscular tone to facilitate intubation. ${ }^{5-8}$ However, there are no data available comparing different induction techniques and their influence on SCh induced increase of jaw muscle tension. The purpose of the present study was to investigate three induction techniques, each of which included the use of SCh to facilitate intubation, with respect to masseter muscle tone, neuromuscular blockade, intubation conditions, and time course of intubation.

\section{Methods}

With institutional approval of the Ethics Committee of the University Hospital of Basel and written, informed consent, we studied 60 ASA physical status I or II patients scheduled for elective ear, nose, and throat surgery. Following an open, prospective, randomized parallel group design, parients were included into the investigation if oral intubation was a necessary procedure, age was between 18 and $60 \mathrm{yr}$, and physical preevaluation showed a normal intubation anatomy according to a Mallampati I-II status. Patients were excluded from the study if they presented without teeth or with loose teeth, with a mouth opening of $<3 \mathrm{~cm}$ between the upper and lower incisors, with an indication for RSI (symptoms of gastric reflux, non-elective procedures), with a desire or need for premedication, or with contraindications for one of the study drugs.

\section{Anaesthetic procedure}

No premedication was given. Using computer generated random numbers, patients were prospectively randomized into the following groups: Group THIO received $5 \mathrm{mg} \cdot \mathrm{kg}^{-1}$ thiopentone, Group THIO/ATR received $0.05 \mathrm{mg} \cdot \mathrm{kg}^{-1}$ atracurium as a precurarization dose five minutes before the administration of $5 \mathrm{mg} \cdot \mathrm{kg}^{-1}$ thiopen- tone (at time $\mathrm{A}_{\mathrm{A}}=-5 \mathrm{~min}$ ), and Group PROP received 2.5 mg.kg-1 propofol. Time $\mathrm{A}_{\mathrm{A}}=0$ (Figure $\mathrm{l}$ ) was defined as beginning of induction of anaesthesia. Twenty milligrams lidocaine were added to all syringes containing the induction agents to reduce pain caused by propofol. All patients were preoxygenated for three minutes and received $3 \mu \mathrm{g} \cdot \mathrm{kg}^{-1}$ fentanyl at the beginning of preoxygenation (at time $_{\mathrm{A}}=-3 \mathrm{~min}$ ). The individual dose of thiopentone or propofol was administered over $10 \mathrm{sec}$ and the time to onset of sleep was monitored, reflecting the time between beginning of injection of induction dose and loss of eyelash reflex. When the eyelash reflex disappeared, the lungs were ventilated five times by mask with $100 \%$ oxygen for approximately $10 \mathrm{sec}$ (tidal volume $500 \mathrm{ml}$ ). Then, a jaw tone myotonometer (Grass force transducer FT 10, Grass Instruments Corp., Quincy MA) was carefully positioned between upper and lower incisors and adjusted so that the direction of force in the jaw was perpendicular to the axis of the transducer (Figure 2). Time requirements for transducer set-up included five seconds for insertion and 5 to $10 \mathrm{sec}$ for baseline recording. When stable baseline recordings were obtained, all patients received 1.5

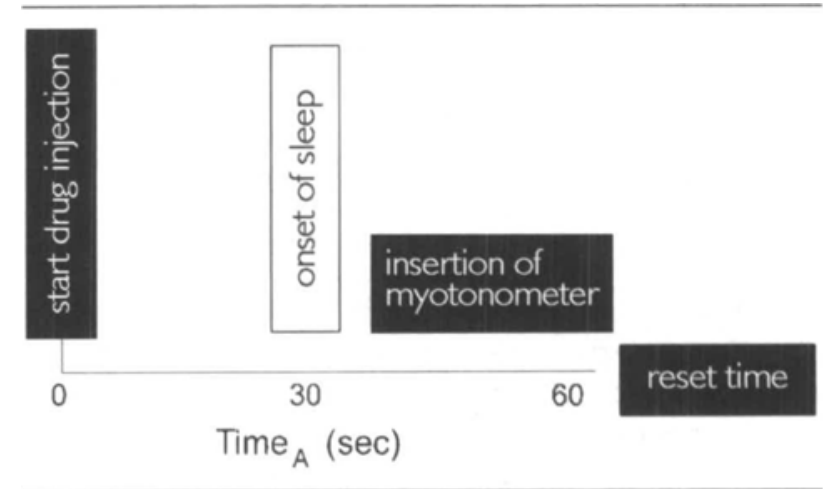

FIGURE 1 Time course of observations and procedures following induction of anaesthesia ( $\left(\mathrm{ime}_{\mathrm{A}}\right.$ )

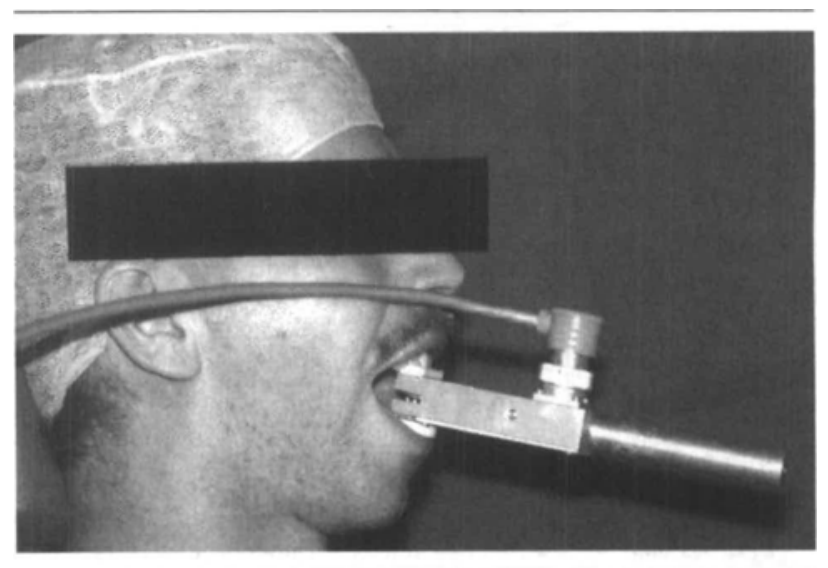

FIGURE 2 Jaw tone measurement (Grass Force Transducer FT10) 
$\mathrm{mg} \cdot \mathrm{kg}^{-1} \mathrm{SCh}\left(\right.$ time $_{\mathrm{B}}=0$; Figure 3). The individual dose was diluted to $5 \mathrm{ml}$ saline and injected within five seconds. Supramaximal (55 mA) transcutaneous stimulation (Dual Stim NS-2C peripheral nerve stimulator; Life Tech Inc., Houston, TX) was applied to the ulnar nerve in the forearm using square waves of $0.2 \mathrm{sec}$ duration at $1 \mathrm{~Hz}$ and twitch response was monitored visually at the adductor pollicis muscle. After disappearance of visual twitch response, the force transducer was removed and laryngoscopy and intubation were performed.

\section{Measurements}

Time measurement started from the beginning of induction of anaesthesia and was recorded continuously up to tracheal intubation (Figures 1,3). According to slight differences in time requirements for ventilating the lungs, insertion of the force transducer, and baseline tension registration (20-25 sec), time measurements for masseter muscle tone registration are shown separately and begin with the administration of SCh at time $e_{B}=0$. Time ${ }_{B}$ measurements included onset of positive jaw tone, peak ( $50 \%$ increase and $50 \%$ decrease of peak jaw tone), and return to post-SCh baseline of jaw tension (offset positive jaw tone). Beginning and offset of fasciculations in the face and lower limbs, intensity of muscle fasciculation (vigorous - moderate - none), and disappearance of twitch response were visually evaluated by a staff member from the Department of Anaesthesia who was not involved in the anaesthetic procedure.

The Grass force transducer FT10 with a diameter of $3 \mathrm{~cm}$ was calibrated before each measurement by placing

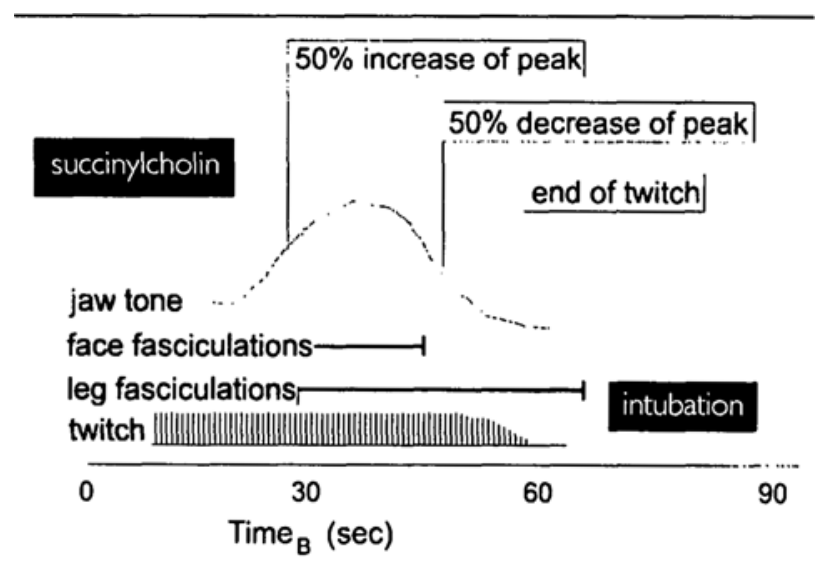

FIGURE 3 Time course of observations and procedures following administration of $\mathrm{SCh}\left(\right.$ time $_{\mathrm{B}}$ )

a $500 \mathrm{~g}(4.9 \mathrm{~N})$ weight on its head, keeping the handle fixed in a horizontal position. Figure 4 shows the calibration procedure on the left side. Jaw muscular preload, which was considered to be masseter resting tension plus distending increase following transducer insertion, was recorded on paper and regarded as baseline for subsequent changes. Jaw tone measurements included the force recorded following insertion of the transducer (preload), peak tension following SCh administration, and afterload (tension following the offset of positive jaw tone). Figures 3 and 4 demonstrate time course of jaw tension including time points of $50 \%$ maximum contracture increase and decrease, respectively.

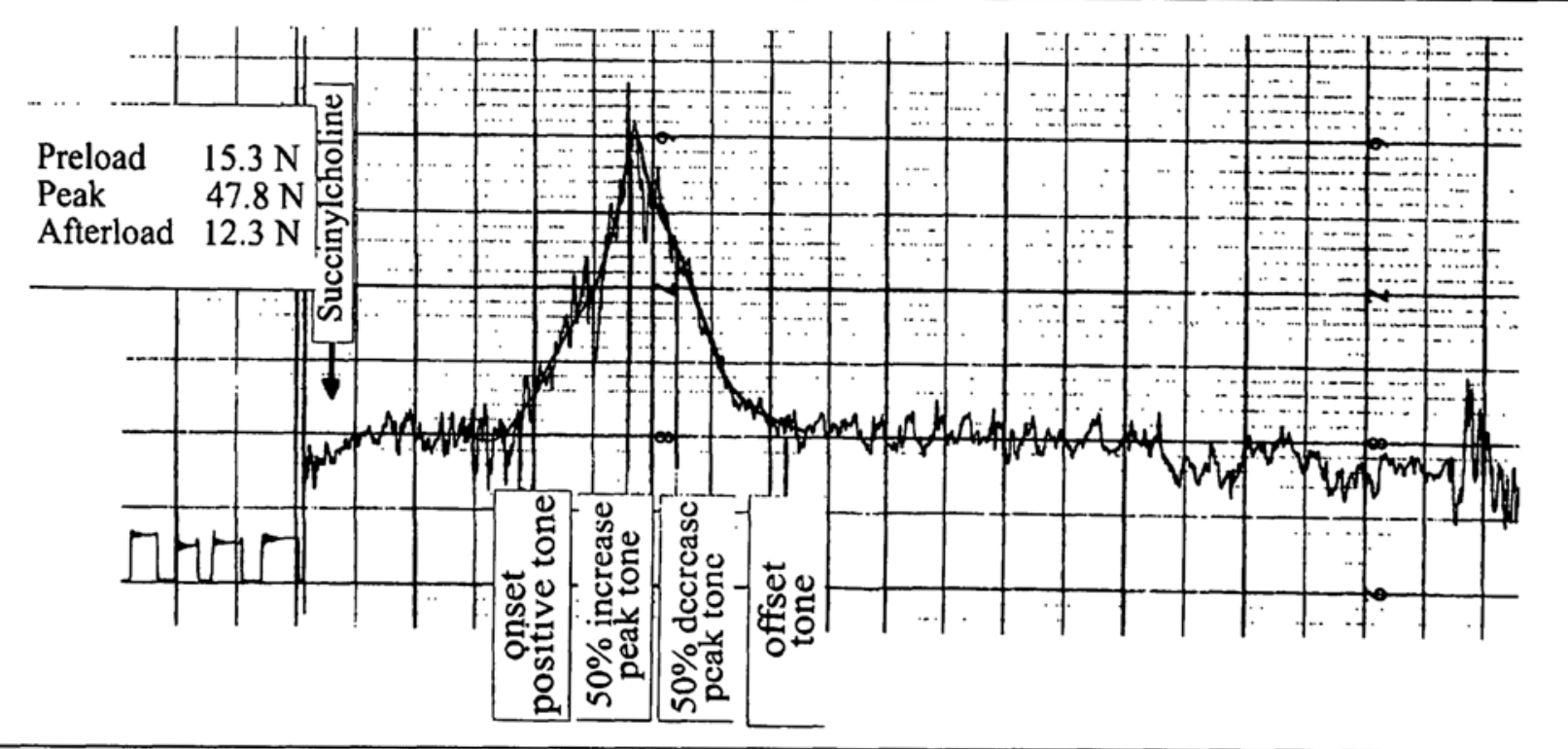

FIGURE 4 Original recording of jaw tension during study period $(12 \mathrm{~cm} \cdot \mathrm{min})$. Square waves on the left represent calibration of the force transducer. 
Conditions for tracheal intubation were scored when the visual twitch response had disappeared (Table I).

\section{Statistics}

Statistical analyses of demographic data, time courses, and jaw tone measurements among the three groups were performed by analysis of variance (ANOVA), Bonferroni correction, chi-squared test, or Fisher's exact test, as appropriate. For statistical analysis of jaw tone measurements, the logarithm of the response was used to obtain an approximately normal distribution. A $P$ value $<0.05$ was considered significant. Results are expressed as mean $\pm \mathrm{SE}$, and median for ordinal values.

\section{Results}

One patient in the THIO group did not tolerate insertion of the force transducer following the induction dose and was excluded from the study. Demographic data did not differ among the three groups with respect to gender, age, weight, or height (Table II).

There was no difference in the onset time of sleep ( time $_{\mathrm{A}}$ ) among groups (THIO $33 \pm 2 \mathrm{sec}$, THIO/ ATR $30 \pm 2 \mathrm{sec}$, PROP $35 \pm 2 \mathrm{sec}$; NS).

Masseter preloads after induction of anaesthesia and insertion of the myotonometer were similar in all three groups (Group PROP $12.7 \pm 1.6 \mathrm{~N}$; Group THIO 16.4 $\pm 2.1 \mathrm{~N}$; Group THIO/ATR $15.1 \pm 2.0 \mathrm{~N} ; P=\mathrm{NS}$ ). An original recording of jaw tension course is shown in Figure 4. Following administration of SCh, all three groups demonstrated increases in jaw tension $(P=$ $0.0001)$. The increase of masseter tone was higher in Group THIO $(12.4 \pm 3.0 \mathrm{~N})$ than in Group

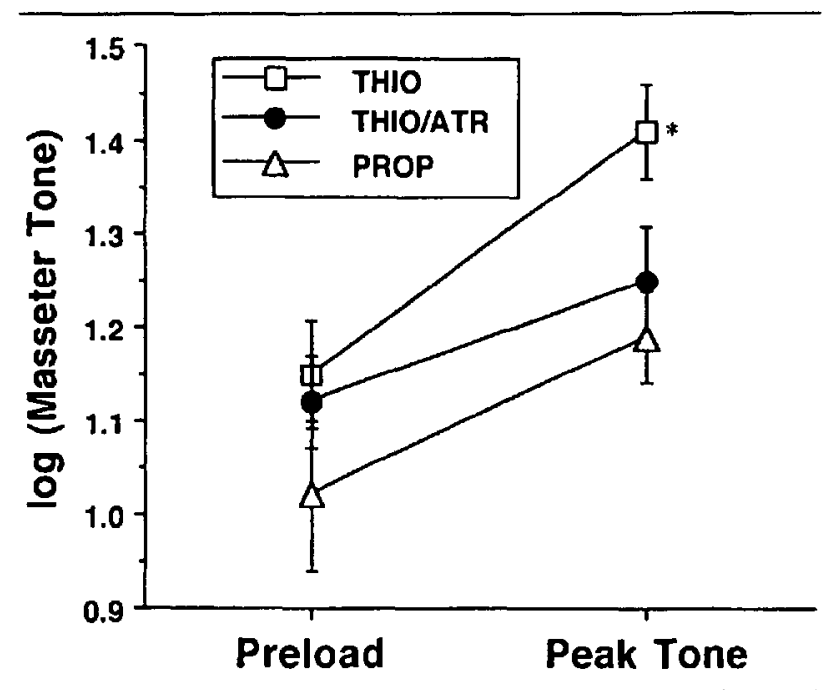

FIGURE 5 Mean log of masseter tone for preload and peak tone. Values are the mean \pm SE. Preload: NS $(P=0.34)$. Peak tone: $P=0.02$ (THIO $^{*}$ w THIO/ATR, PROP), LSD test
THIO/ATR $(6.4 \pm 2.1 \mathrm{~N})$ or in Group PROP $(5.0 \pm$ $1.1 \mathrm{~N} ; P<0.05$ ). Peak masseter tone differed (one-way ANOVA of $\log$ peak, $P=0.02$ ) among the groups (Figure 5).

A massive increase in masticatory tone was a rare event following propofol induction: Only 4 of 20 patients showed $>\mathbf{5 0} \%$ and only two of them $>100 \%$ increase of baseline tension after SCh (Figure 6). We did not observe any symptoms of hypermetabolic reactions such as tachycardia, hypercapnia, or temperature increase in our patients.

Clinical evaluation of muscle fasciculation showed the same intensity in Group THIO and Group PROP (face 1, feet 1; median; NS), whereas Group THIO/ATR

TABLE I Intubation conditions

\begin{tabular}{cl}
1 Excellent & $\begin{array}{l}\text { Jaws relaxed } \\
\text { Vocal cords apart and immobile } \\
\text { No disphragmatic movement } \\
\text { Slight resistance of jaws } \\
\text { Slight moving of cords or } \\
\text { Slight coughing } \\
\text { Acceptable }\end{array}$ \\
& $\begin{array}{l}\text { Clear masseter resistance } \\
\text { Cords moving or closed } \\
\text { Coughing and bucking }\end{array}$ \\
\hline
\end{tabular}

TABI.E II Demographic data

\begin{tabular}{lllll}
\hline & $\begin{array}{l}\text { THIO } \\
(n=19)\end{array}$ & $\begin{array}{l}\text { THIO/ATR } \\
(n=20)\end{array}$ & $\begin{array}{l}\text { PROP } \\
(n=20)\end{array}$ & \\
\hline Age $(\mathrm{yr})$ & $31(18-51)$ & $34(19-57)$ & $33.6(19-46)$ & NS \\
Height $(\mathrm{cm})$ & $175 \pm 2$ & $172 \pm 2$ & $174 \pm 2$ & NS \\
Weight $(\mathrm{kg})$ & $75 \pm 3$ & $75 \pm 3$ & $71 \pm 3$ & NS \\
Sex $(\mathrm{m}, \mathrm{f})$ & $\mathrm{m}=13, \mathrm{f}=6$ & $\mathrm{~m}=13, \mathrm{f}=7$ & $\mathrm{~m}=14, \mathrm{f}=6$ & $\mathrm{NS}$ \\
\hline
\end{tabular}

Values stated are mean $\pm S E$, or range

$\mathrm{m}=$ male, $\mathrm{f}=$ female

NS = not significant (One-way ANOVA, Chi-Square)

TABLE III Time course (sec) of observations after beginning of SCh administration

\begin{tabular}{lllll}
\hline & $\begin{array}{l}\text { THIO } \\
(n=19)\end{array}$ & $\begin{array}{l}\text { THIOATR } \\
(n=20)\end{array}$ & $\begin{array}{l}\text { PROP } \\
(n=20)\end{array}$ \\
\hline Onset positive jaw tone & $27 \pm 3$ & $31 \pm 2$ & $29 \pm 2$ & NS \\
$50 \%$ increase peak jaw tone & $33 \pm 3$ & $37 \pm 2$ & $35 \pm 3$ & NS \\
50\% decrease peak jaw tone & $46 \pm 4$ & $43 \pm 3$ & $47 \pm 3$ & NS \\
Offset positive jaw tone & $58 \pm 5$ & $52 \pm 5$ & $56 \pm 4$ & NS \\
Disappearance of visual twitch & $72 \pm 3$ & $77 \pm 4$ & $71 \pm 3$ & NS \\
End/face fasciculations & $46 \pm 3$ & $47 \pm 3$ & $45 \pm 2$ & NS \\
End/leg fasciculations & $\mathbf{7 8} \pm 4$ & $81 \pm 6$ & $73 \pm 4$ & NS \\
\hline
\end{tabular}

Values stated are mean $\pm \mathrm{SE}$

NS = not significant (One-way ANOVA) 
showed a lower intensity of fasciculations (face 0 , feet 0 ; median; $P<0.05)$. Absence of fasciculations was observed in 16 patients in Group THIO/ATR compared with only one patient in Group THIO and no patient in Group PROP. Following the beginning of SCh administration, fasciculations in the face began earlier $(27 \pm 1$ sec) than in the feet $(37 \pm 2 \mathrm{sec}), P<0.0001$, and also persisted in the face for a shorter time $(19 \pm 2 \mathrm{sec})$ than in the lower extremities $(39 \pm 3 \mathrm{sec}), P<0.0001$.

Figures 1 and 3 illustrate the time course of observations following induction of anaesthesia ( time $_{A}$ ) and after administration of SCh $\left(\mathrm{time}_{\mathrm{B}}\right)$. There were no differences among the groups in the time courses of action of SCh: Time points of onset of positive jaw tension, $50 \%$ increase of peak tone, $50 \%$ decrease of peak tone, offset of positive tone, and onset and end of fasciculations on face and lower extremities, as well as disappearance of visually monitored twitch response were comparable among the groups (Table III). Also, the time from administration of SCh to intubation did not differ (THIO $127 \pm 7 \mathrm{sec}$, THIO/ATR $123 \pm 6 \mathrm{sec}$, PROP $118 \pm 8 \mathrm{sec}$ ). At the time of cessation of facial fasciculation, $70 \%$ of patients still had $>50 \%$ peak masseter tension compared with $2 \%$ and $3 \%$ at the time of visual twitch loss or the end of fasciculation of the feet, respectively.

\section{Discussion}

The results of this study show that the degree of SChinduced increase in masseter tension can be modified by the choice of the induction agent. Propofol diminished the jaw tone increase after SCh administration to a similar degree as a precurarization dose of atracurium together with thiopentone compared with thiopentone alone. Onset time of sleep was independent of the induction procedure. Cessation of facial fasciculations is a poor index of good intubation conditions, because, at this time, most patients still demonstrate high masseter tension, whereas, at disappearance of visual twitch of the adductor pollicis muscle following ulnar stimulation, peak jaw tension had already passed in $98 \%$ of the patients.

An increase in masticatory muscle tone after administration of SCh when combined with volatile anaesthetics has been demonstrated by various investigators. ${ }^{9,10}$ In children, SCh increased upper airway muscle tone following propofol induction independent of the presence of volatile anaesthetics. ${ }^{11}$ Propofol has become widely used for intravenous induction of anaesthesia and produces adequate intubating conditions without the use of muscle relaxants. ${ }^{3}$ Comparing the effects of thiopentone and propofol on upper airway integrity, the ease of laryngoscopy and absence of tracheal response is more common after propofol induction. ${ }^{4,12}$ The presence of
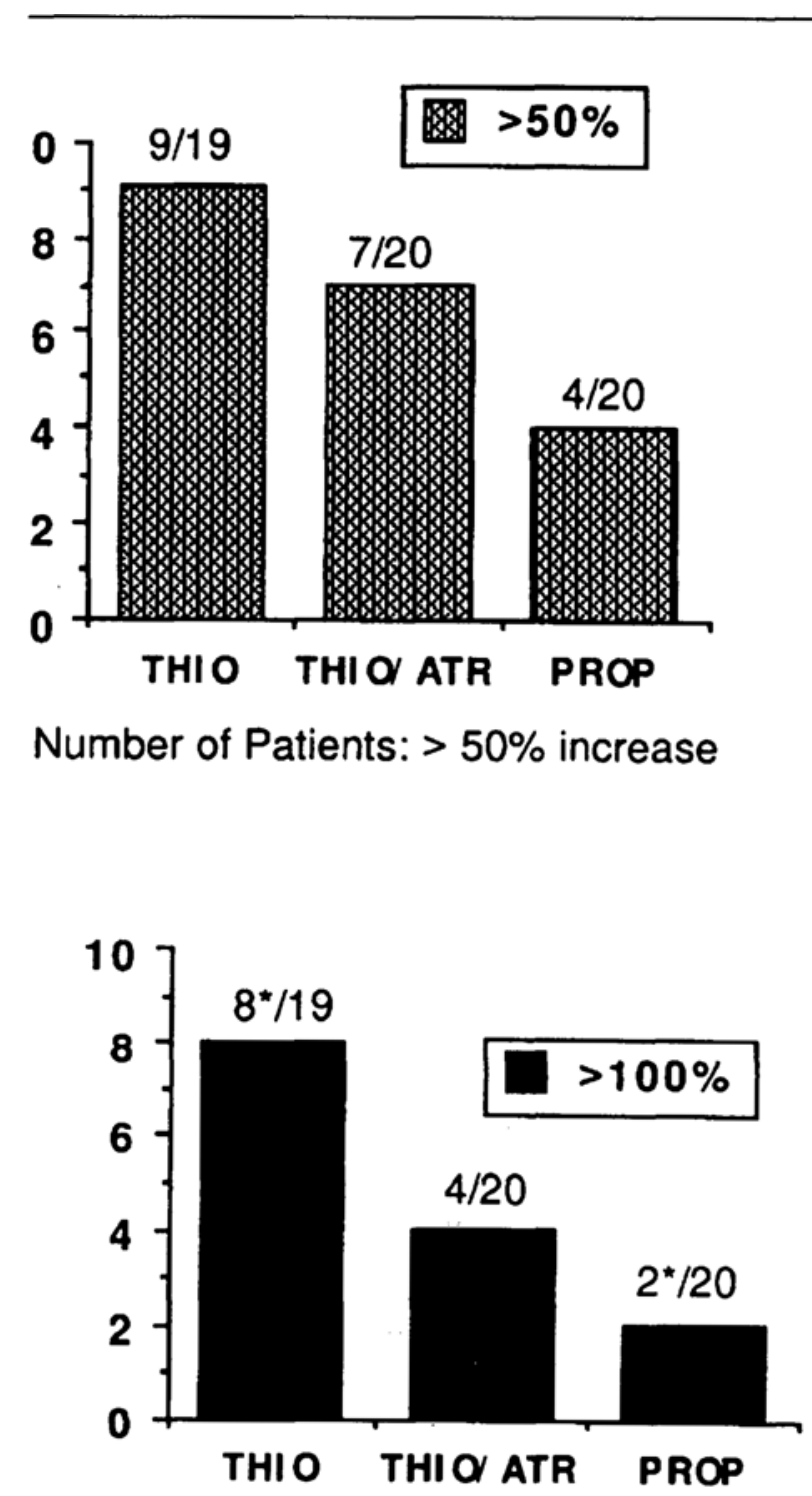

Number of Patients: $>100 \%$ increase

FIGURE 6 Number of patients per group demonstrating greater than $50 \%$ (Fisher's Exact Test: $P=$ NS) or greater than $100 \%$ (Fisher's Exact Test. THIO vs PROP: $P<0.05$; THIO vs THIO/ATR: $P=$ NS) increase in masseter tone following succinylcholine administration.

thiopentone is believed to exert a protective effect on masseter muscle rigidity ${ }^{13}$ but, in this context, the results of the present study suggest that propofol would be the more protective drug. Even though masseter spasm is less likely to occur following thiopentone and SCh than after halothane and SCh administration, ${ }^{13}$ Marohn and Nagia presented a case report of unexpected masseter muscle rigidity after a RSI with thiopentone and SCh. ${ }^{14}$ In our investigation, baseline muscle tensions in the 
three groups were not statistically different, but the propofol group exhibited the lowest mean tension. Thus, the lower increase of masseter tension after SCh administration in the propofol group may reflect a smaller baseline muscle tension following induction of anaesthesia with propofol. This may be explained, in part, by its inhibitory effects on the calcium release channel of the sarcoplasmic reticulum in skeletal muscle. ${ }^{15}$ Perhaps a larger population size than was used in our study would have revealed significant differences in jaw tone before SCh treatment.

We investigated the effect of SCh on jaw tone following intravenous induction with propofol, thiopentone, and thiopentone in combination with a subparalyzing dose of atracurium, although we note that controversy exists about drug choice, dose, timing, and clinical benefit of precurarization. ${ }^{16}$ With halothane/nitrous oxide induction, pretreatment with non-depolarizing neuromuscular blocking agents does not prevent $\mathrm{SCh}$-induced increases in resting jaw tension in children. ${ }^{9}$ On the other hand, despite halothane anaesthesia, a defasciculating dose of vecuronium almost completely blocks the SCh-induced masseter muscle contracture in rats. ${ }^{17}$ In the present study with adult patients, the defasciculating dose of atracurium did not prevent the increase of jaw tone following intravenous induction and SCh administration, but diminished its magnitude.

As previously described, ${ }^{10,18}$ we also observed a wide range of masseter responses to $\mathrm{SCh}$ (range of increase of tension 0 to $45.1 \mathrm{~N}$ ), suggesting extreme variability within a normal population. Because of the variation in muscle tone after $\mathrm{SCh}_{\text {, }}$ analysis of covariance (ANCOVA) should be used for statistical comparison. However, an ANCOVA assumes that the covariate (e.g. preload) is a measurement taken before the treatments are applied which are thought to predict the final response. ${ }^{19}$ This was not true in our study, since the baseline tension measurement was taken after the induction treatment was applied. We, therefore, performed logarithmic transformation of our tension measurements to obtain approximately normal distribution for using ANOVA.

The increased masseter tensions in a paediatric population have been shown to be about $0.5 \mathrm{~N}$ after a dose of $1 \mathrm{mg} \cdot \mathrm{kg}^{-1} \mathrm{SCh}$; such increases were easily overcome by the laryngoscopist. ${ }^{20}$ However, using a strain gauge based sensor laryngoscope, Bucx et al. described a maximum force range from 16 to $36 \mathrm{~N}$ applied during laryngoscopy in children. ${ }^{11}$ Thus, jaw tone increases of $12.4 \pm 3.0 \mathrm{~N}$, as seen in our THIO group, might be of some clinical importance. Furthermore, in some patients with extreme values, increased resting tension, or stiffness of the muscles moving the mandible could make laryngoscopy difficult ${ }^{21}$ if performed too early. Even though some patients exhibited a response of sufficient magnitude to be detected by the anaesthetist, we did not encounter any cases of difficult intubation within our study group. But, according to the study protocol, laryngoscopy was not performed during the period of increased masseter tension and time course of intubation did not differ among the groups due to the comparable time points of the observed action of SCh.

Many anaesthetists attempt to open the mouth and intubate the trachea at the end of facial fasciculations, ${ }^{22}$ a time that coincides with the maximum increase in masseter muscle tone. Thus, cessation of facial fasciculation is an unreliable predictor of good intubation conditions. In our investigation, $70 \%$ of patients still demonstrated peak masseter tension at this time. Discrepancy between the timing of the thumb and laryngeal relaxation after SCh has identified the adductor pollicis to be a poor index of tracheal intubation conditions. ${ }^{23} \mathrm{We}$, too, demonstrated a longer time was needed to wait for cessation of leg fasciculations or loss of visual twitch than for offset of positive jaw tone. On the other hand, employment of a peripheral ulnar nerve stimulator and loss of visual twitch control at the thumb are at least safe procedures for monitoring jaw tension. We found that peak masseter tension in $98 \%$ of the patients had already passed by the end of visually evaluated twitch control and $97 \%$ by the end of lower extremities fasciculation. Loss of lower extremity fasciculations and/or waiting for 20-30 sec following the end of facial fasciculations, as previously recommended, ${ }^{1}$ may be alternative strategies for predicting good intubation conditions. Waiting for 73-81 sec (end of leg fasciculations, Table III) following administration of $\mathrm{SCh}$ makes a larger dose of rocuronium an acceptable alternative to SCh for RSI, but potentially dangerous aspects of the longer duration of action must be considered. ${ }^{6}$ In emergency procedures, however, as in obstetric anaesthesia, speed of intubation is essential. ${ }^{24}$ Carnie $e t$ al. investigated the relationship between the time of onset of neuromuscular blockade and the time at which laryngoscopy was attempted in patients presenting for emergency obstetric or general surgical procedures. ${ }^{25}$ They showed that intubation preceded complete neuromuscular blockade and that there was no correlation between these times in obstetric patients. Attempts at tracheal intubation in a patient with incomplete neuromuscular blockade, however, may provoke regurgitation or vomiting. Since SCh-induced blockade is more rapid and more intense in laryngeal muscles than in the adductor pollicis, ${ }^{26}$ the decreased masseter tension following propofol would ease laryngoscopy in cases, such as significant hypox- 
aemia, where the amount of time the anaesthetist can wait is more limited.

In conclusion, increase in masseter motor tone is a normal response to the administration of $\mathrm{SCh}$ and is maximal at the end of facial fasciculations. The results of our study suggest that without the use of a defasciculating dose of a non-depolarizing neuromuscular blocking drug, propofol, compared with thiopentone, may provide better conditions for intubating the trachea with respect to SCh-dependent increase in jaw tension.

\section{Acknowledgments}

We are indebted to Karen Powers and Paul Sampson PhD, Seattle, for their helpful advice in statistical analyses.

\section{References}

1 Leary NP, Ellis FR. Masseteric muscle spasm as a normal response to suxamethonium. $\mathrm{Br}$ J Anaesth 1990; 64: 488-92.

2 Capan LM, Bruce DL, Patel KP, Turndorf $H$. Succinylcholine-induced postoperative sore throat. Anesthesiology 1983; 59: 202-6.

3 Scheller MS, Zornow MH, Saidman LJ. Tracheal intubation without the use of muscle relaxants: a technique using propofol and varying doses of alfentanil. Anesth Analg 1992; 75: 788-93.

4 Stevens JB, Vescovo MV, Harris KC, Walker SC, Hickey $R$. Tracheal intubation using alfentanil and no muscle relaxant: is the choice of hypnotic important? Anesth Analg 1997; 84: 1222-6.

5 Bevan DR. Succinylcholine (Editorial). Can J Anaesth 1994; 41: 465-8.

6 Magorian $T$, Flannery $K B$, Miller $R D$. Comparison of rocuronium, succinylcholine, and vecuronium for rapidsequence induction of anesthesia in adult patients. Anesthesiology 1993; 79: 913-8.

7 Martin C, Bonneru J-J, Brun J-P, Albanese J, Gouin F. Vecuronium or suxamethonium for rapid sequence intubation: which is better? $\mathrm{Br}$ J Anaesth 1987; 59: 1240-4.

8 Stone DJ, Gal TH. Airway management. In: Miller RD (Ed.). Anesthesia, 4th ed. New York: Churchill Livingstone Inc., 1994: 1416-7.

9 Smith CE, Saddler JM, Bepan JC, Donati F, Bevan DR. Pretreatment with non-depolarizing neuromuscular blocking agents and suxamethonium-induced increases in resting jaw tension in children. Br J Anaesth 1990; 64: 577-81.

10 Van Der Spek AFL, Fang WB, Ashton-Miller JA, Stobler CS, Carlson DS, Schork MA. The effects of succinylcholine on mouth opening. Anesthesiology 1987; 67: 459-65.

11 Bucx MJL, Van Geel RTM, Meursing AEE, Stijnen $T$, Scheck PAE. Forces applied during laryngoscopy in children. Are volatile anaesthetics essential for suxam- ethonium induced muscle rigidity? Acta Anaesthesiol Scand 1994; 38: 448-52.

12 McKeating K, Bali IM, Dundee JW. The effects of thiopentone and propofol on upper airway integrity. Anaesthesia 1988; 43: 638-40.

13 Lazzell VA, Carr AS, Lerman J, Burrows FA, Creighton $R E$. The incidence of masseter muscle rigidity after succinylcholine in infants and children. Can J Anaesth 1994; 41: 475-9.

14 Marobn $M L$, Nagia $A H$. Masseter muscle rigidity after rapid-sequence induction of anesthesia. Anesthesiology $1992 ; 77: 205-7$

15 Mickelson JR, Louis CF. Malignant hyperthermia: excitation-contraction coupling, $\mathrm{Ca}^{2+}$ release channel, and cell $\mathrm{Ca}^{2+}$ regulation defects. Physiol Rev 1996; 76: 537-92.

16 Pinchak AC, Smith CE, Shepard LS, Patterson L. Waiting time after non-depolarizing relaxants alter muscle fasciculation response to succinylcholine. Can J Anaesth 1994; 41: 206-12.

17 Shi $\Upsilon$, Storella RJ, Keykbah MM, Rosenberg $H$. Antagonism of suxamethonium-induced jaw muscle contracture in rats. $\mathrm{Br}$ J Anaesth 1997; 78: 332-3.

18 Smith $C E$, Donati $F$, Bevan DR. Effects of succinylcholine at the masseter and adductor pollicis muscle in adults. Anesth Analg 1989; 69: 158-62.

19 Cochran WG. Analysis of covariance: its nature and uses. Biometrics 1957; 13: 261-81.

20 Plumley MH, Bevan JC, Saddler JM, Donati F, Bevan DR Dose-related effects of succinylcholine on the adductor pollicis and masseter muscles in children. Can J Anaesth 1990; 37: 15-20.

21 Brandom $B W$. Atracurium and succinylcholine on the masseter muscle (Editorial). Can J Anaesth 1990; 37: 7-11.

22 Yemen TA. Are we obsessed with masseter muscle rigidity? Temporomandibular joint disease mistakenly diagnosed as masseter muscle rigidity on two separate occasions in one patient. Anesth Analg 1993; 77: 848-50.

23 Donati $F$, Bepan $D R$. Not all muscles are the same (Editorial). Br J Anaesth 1992; 68: 235-6.

24 Doughty $A$. Anaesthesia for operative obstetrics and gynaecology. In: Churchill-Davidson HC (Ed.). A Practice of Anaesthesia, 4th ed. London: Lloyd-Luke (Medical Books) Ltd., 1978: 1366.

25 Carnie JC, Street MK, Kumar B. Emergency intubation of the trachea facilitated by suxamethonium. $\mathrm{Br} \mathrm{J}$ Anaesth 1986; 58: 498-501.

26 Meistelman $C$, Plaud B, Donati F. Neuromuscular effects of succinylcholine on the vocal cords and adductor pollicis muscles. Anesth Analg 1991; 73: 278-82. 